\title{
Romania's foreign trade with the European Union in 2008
}

\author{
Stângaciu Oana Ancuța, "Vasile Alecsandri” University of Bacau, Romania
}

\begin{abstract}
In this study, I proposed to analyze the spatial concentration of international trade flows between Romania and the European Union both overall and by the sections of the Combined Nomenclature. Using statistical analysis methods such as square and Gini's index or Onicescu informational energy, I concluded that Romania's main trade partners are Italy, Germany and France and trade relations with these 3 countries are characterized by exchanges of good to cover, generally a wide range of products.
\end{abstract}

\section{Keywords}

Export FOB, CIF imports, trade balance, concentration of foreign trade: Gini Index, Onicescu informational energy

JEL Codes: C10, F10, F49, O11

\section{Romania's FOB exports with EU}

Romania's FOB exports in 2008 amounted to 33.724 .570 thousand Euro, of which 70,4\% of total exports were destined for EU member states. Analyzing Figure 1 is apparent, first, that Romania's main export markets were Germany ( $23,5 \%$ of the country's total exports), Italy (21,9\% of total exports of the country), France (10,5\% of total exports of the country) and Hungary ( $7,2 \%$ of total exports of the country) and secondly that Romania is focus on a few export partner contries (in 5 state Romania exporting $69,0 \%$ of total export) given that Romania's export markets are all EU Member States.

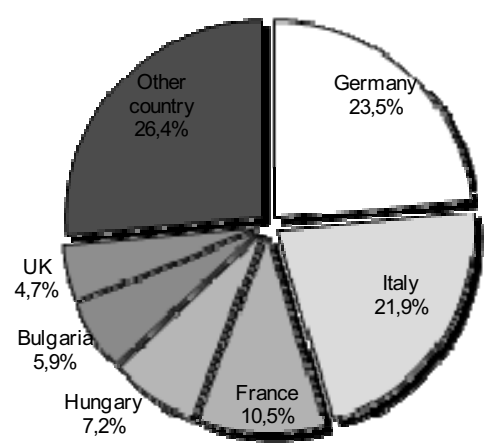

Figure 1. The structure of the export by member States of the EU, in $2008(\%)$ Source: processing by Romanian foreign trade yearbook, National Institute of Statistics, Bucharest

Evolution in exports by sections of the Combined Nomenclature 
The main sections of merchandise for exports in 2008 were:

- machinery and electrical appliances $(24,0 \%$ of the total). From the total section, in the last three years, over $82,0 \%$ were exports towards EU;

- base metals $(14,7 \%$ of the total), of which almost $60 \%$ in the EU States. Almost $50 \%$ were exports of Pig-iron, iron and steel, and $23 \%$ products of Pig-iron, iron and steel;

- vehicles $(12,4 \%$ of the total), increasing in the last three years. Of the total, over $60 \%$ were exports towards EU States;

- textiles $(10,5 \%$ of the total). This stood for between $21-26 \%$ of the exports in the period 1996-2004, being in a visible decrease in the last 3-4 years. Exports to the EU represent between $90-94 \%$ of the total;

- mineral products $(9,4 \%$ of total exports from last year, compared to $14,5 \%$ at the beginning of the period). If the share of the member States was 6,9\% in 1991, 24\% in 1992, it increased to $36 \%$ in the last year. Over $97 \%$ of the total exports of this section represent fuel and mineral oils, and only $1,4 \%$ salt, stone, lime, cement;

- plastics (5\% of total exports, $70 \%$ of that being exports to the member States);

- chemical products $(4,2 \%$ of total exports, down from a peak of $9,7 \%$ in 1992). The member States, from $20-25 \%$ share in the early years, rose to almost $50 \%$ in the last year. Of a total section, $34 \%$ represent exports of fertilizers, $23 \%$ of organic products, inorganic products $16 \%, 7-8 \%$ pharmaceuticals and essential oils.

\section{Romania's CIF imports with EU}

CIF imports in Romania in 2008 the value of 57.240 .310 thousand Euro, of which $69,1 \%$ of total imports had the provenance area of the EU Member States. Germany is the main source of imports for Romania (23,6\% of Romania's total imports), followed by Italy (16,4\% of total imports), Hungary (10,7\% of total imports) and France ( $8,2 \%$ of total imports). As to the exports, it appears that the largest share $(65,9 \%)$ of Romania's imports comes from the first 5 partener countries, even trough Romania import goods from all EU Member States.

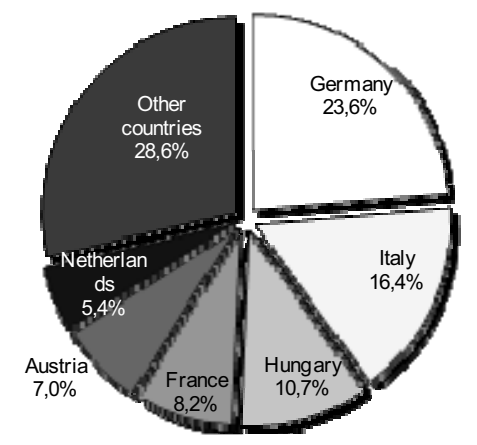

Figure 2. The structure of the import by member States of the EU, in 2008 (\%)

Source: processing by Romanian foreign trade yearbook, National Institute of Statistics, Bucharest

Evolution in imports by sections of the Combined Nomenclature

The main sections of import in 2008 were:

- Machinery and electrical applicants (24\% of the total). Of the total section, in the last two years, about $80 \%$ were imports from the E.U.;

- Means of transport (12,4\% of the total), increasing in the past two years. Of the total, over $86 \%$ were imports from the E.U.;

- Common metals $(11,3 \%$ of the total), of which about 65 in the E.U. Almost $34 \%$ were imports of products made of raw iron, iron, steel, and 33\% of raw iron, iron and steel; 
- Chemical products $(8,3 \%$ of total imports, down from about 8\% during 2000-2003 to $7,5 \%$ in subsequent years). Member States, from approximately $64 \%$ share in the years around 2000 , have reached nearly $80 \%$ last year. Of the total section, $40 \%$ stands for imports of pharmaceuticals, $11 \%$ of essential oils, $10 \%$ of colored extracts, $7 \%$ of soap and washing preparations.

- Textile products ( $6 \%$ of the total). They were between $15-16,5 \%$ of the imports in 2000-2002, being in a visible decrease in the last 3-4 years, reaching 7-8\%. Imports from the E.U. represent $82 \%$ of the total in the last year, standing in all these years around $80 \%$;

- Mineral products (13,9\% of total imports last year, maintaining approximately at the same level compared to the beginning of the period). If the share of the Member States was $6,4 \%$ in 2000 , it rose to $11,5 \%$ in the last year. Over $85 \%$ of total imports of this section is represented by fuel and mineral oils and around $9 \%$ by salt, stone, lime, cement;

- Plastics (5,7\% of total imports, of that over $80 \%$ being imported from the States);

\section{Concentration of foreign trade}

The usage of statistical methods to study the phenomena of concentration can complete the analysis of the structure of foreign trade, both by sections and by E.U. Member States. Measuring the degree of concentration can be done both through numerical and graphical methods. The graphical way supposes the construction of a graphical curve of concentration - Lorentz-Gini curve- and based on it, we can find out the degree of concentration by determining a coefficient - Gini index.

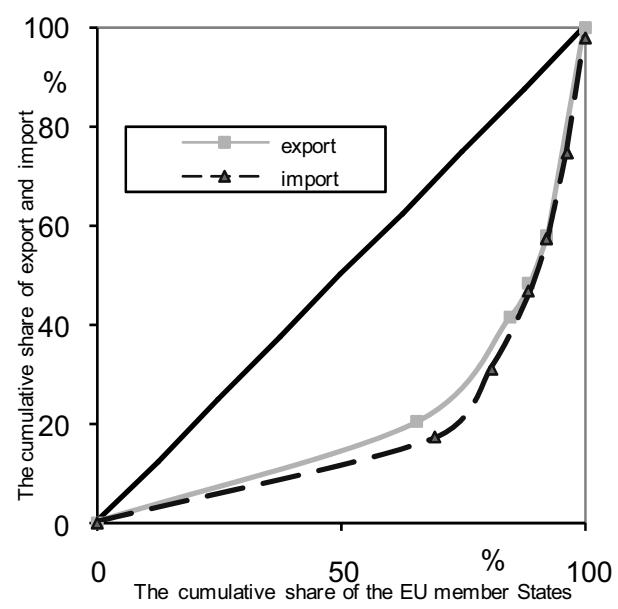

Figure 3. The concentration curve of exports and imports in 2008

Source: processing by Romanian foreign trade yearbook, National Institute of Statistics, Bucharest

The concentration curve is the graphical representation of the $q$ variable depending on the variable $p$, where $p$ represents the relative cumulative herds of the E.U. states, and $q$ stands for the global, cumulative and relative values of import and export. The concentration curve, constructed by unifying the points of coordinates, is shown in a square, also known as Gini's square. The degree of concentration may be approximated depending on the size of the area of concentration, namely, the farthest the curve of concentration from the square's diagonal, the higher the concentration surface, thus the disparities between the E.U. countries for the exports and imports, and the concentration degree of the country is stronger.

In our case, the Gini's square highlights a high degree of concentration of the foreign trade by E.U. member states; the concentration degree being slightly higher for imports than for 
exports. From the graph there can be detached three distinct qualitatively types of states. Thus, for the intra-community exports are the following three groups:

1. The group of the few, $15,4 \%$ of the E.U. States (Germany, Italy, France and Hungary), to which are focused most of Romania's exports, $58,7 \%$.

2. The middle group, a more balanced one, comprising 19,2\% of the States (Bulgaria, the United Kingdom, Spain, Austria and Poland) to which are exported 20,9\% of the total intra-community exports of Romania;

3. The group of the most to which less is exported, thus towards $65,4 \%$ of the Union States (all the 17 remaining States) there is exported only $20,4 \%$ of the total intra-community exports of Romania.

For imports, the three groups are formed as follows:

1. The group of the few, $19,2 \%$ of the E.U. (Germany, Italy, Hungary, France and Austria), to which are focused most of the intra-community imports of Romania, $68,8 \%$.

2. The middle group, more balanced, comprising $11,6 \%$ of the States (Netherlands, Poland and Czech Republic) from which is imported 13,9\% of the total intra-community imports of Romania;

3. The group of the most from which less is imported, from $69,2 \%$ of the E.U. States (all the 18 remaining States) is imported only $17,3 \%$ of the total intra-community imports of Romania.

Gini index of concentration is a synthetic indicator of the concentration of a distribution and is defined as a relation between two surfaces: area of concentration - the area between the curve of concentration and the diagonal of the Gini square - and the area of the square. The value of the index of concentration is always between 0 and 1 , respectively between $0 \%$ and $100 \%$, reflecting the variation in the degree of concentration of the phenomenon from a null concentration to a maximum one.

The index of concentration calculated for export is $55 \%$ and for import is $61 \%$, confirming a very high degree of concentration of the foreign trade of Romania with the E.U. States.

The same analysis was done by sections, both for export and import. Applying the Onicescu method (the corrected formula of calculation, denoted by E) to analyze the degree of concentration of exports and imports from Romania by sections, for each State, resulted that in the final year of the analysis, there was a very small level of concentration of exports and imports on certain sections.

$$
E=\frac{\sum g_{i}^{2}-\frac{1}{N}}{1-\frac{1}{N}} \rightarrow(1)
$$

where $g_{i}$ is the share of import / export from a section of the total import / export of a country, and $\mathrm{N}$ is the number of sections, 19 in our case.

In total, the Onicescu informational energy was 0,089 for exports and of 0,095 for imports, highlighting a relatively uniform distribution of the imports and exports by sections.

The highest degrees of concentration were recorded in Luxembourg for exports, the concentration index being 0,77 . Basically in this case, $88 \%$ of the exports of Romania towards Luxembourg were performed in a single section, means of transport. Same issue in the case of Ireland, where the index is 0,41 and $65 \%$ of the exports to this State were done also with means of transport. 


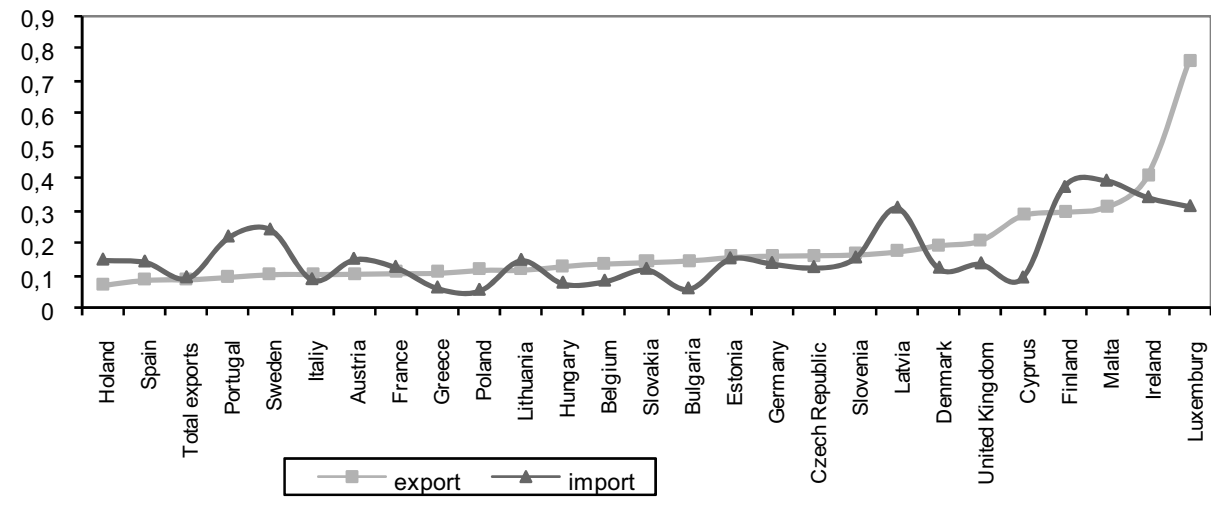

\section{Figure 4. Concentration of the foreign trade by sections of the Combined Nomenclature and by member states of the EU, in 2008 (the value of the Onicescu informational energy - the corrected formula) \\ Source: processing by Romanian foreign trade yearbook, National Institute of Statistics, Bucharest}

Next I applied the same formula for the Onicescu energy, but with other meanings: $\mathrm{g}_{\mathrm{i}}$ is the share of each State in the import / export of a total section and $\mathrm{N}$ is the number of partner states, respectively 26 .

It was obtained the concentration graph below, which expresses the degree of concentration of external trade by Member States, within each section of the Combined Nomenclature of products.

The highest degrees of concentration, both for import and export are observed in the following sections:

- Footwear, where the Onicescu informational energy is 0,43 for export and 0,47 for import. This is mainly due to the majority share of exports to Italy ( $66 \%$ of the total) followed by Germany $(10 \%)$ and in the case of imports $70 \%$ of the total come from Italy and $8 \%$ from Germany;

- Raw hides, tanned, where the Onicescu informational energy is 0,41 for export and 0,52 for import. In this case, $64 \%$ of Romania's exports go to Italy and $10 \%$ to Germany. Meanwhile, $72 \%$ of the imports come from Italy and $8 \%$ from Germany;

- Mineral products, where the Onicescu informational energy is somehow higher for the export $(0,20)$ than for imports $(0,07)$. Of the total mineral products exported around $43 \%$ go to Bulgaria and $15 \%$ to Hungary and Slovenia. Imported, they come up to $27 \%$ from Poland and 21\% from Hungary;

In the other sections we can not speak of a high degree of concentration by States, but there can be emphasized some partners with slightly higher shares of external trade in those products. Thus, in the case of:

- Textiles, $36 \%$ of exports have as destinations Italy, $22 \%$ Germany, $12 \%$ France and $11 \%$ the United Kingdom. As imports, textiles are mainly from Italy (40\%) and Germany $(22 \%)$, being visible in this case the influence of lohn production, which makes exports to depend on imports;

- Wood products are intended mainly to Italy (30\%), Germany (9\%) and Spain (9\%) and as imports they come up to $25 \%$ from Germany, $15 \%$ from Poland, $15 \%$ from Austria and also $15 \%$ from Hungary;

- Paper and articles of paper are exported to more than $23 \%$ to France, $19 \%$ to Italy, $13 \%$ to Bulgaria and $12 \%$ to Greece. As imports, they are mainly from Germany $(22 \%)$, Italy $(16 \%)$ and Poland (11\%);

- Food products are exported mainly to Italy (29\%), Bulgaria (16\%) and Hungary (14\%) and as imports them come from: Hungary (20\%), Germany (16\%) and Poland (11\%) 
- Mineral products are exported mainly to Bulgaria (43\%), Slovenia (15\%) and Hungary (15\%). Imports are mainly originated from Poland (27\%) and Hungary (21\%);

- Chemical products are exported mainly to Italy $(21 \%)$, Germany (16\%), Hungary $(13 \%)$ and imports come from Germany $(21 \%)$, France $(13 \%)$ and Italy $(8 \%)$;

- Plastics are exported mainly to Germany and Italy (18\% each), France and Hungary (12\% each), while imports came from Germany (25\%), Italy (14\%) and Hungary (12\%) .

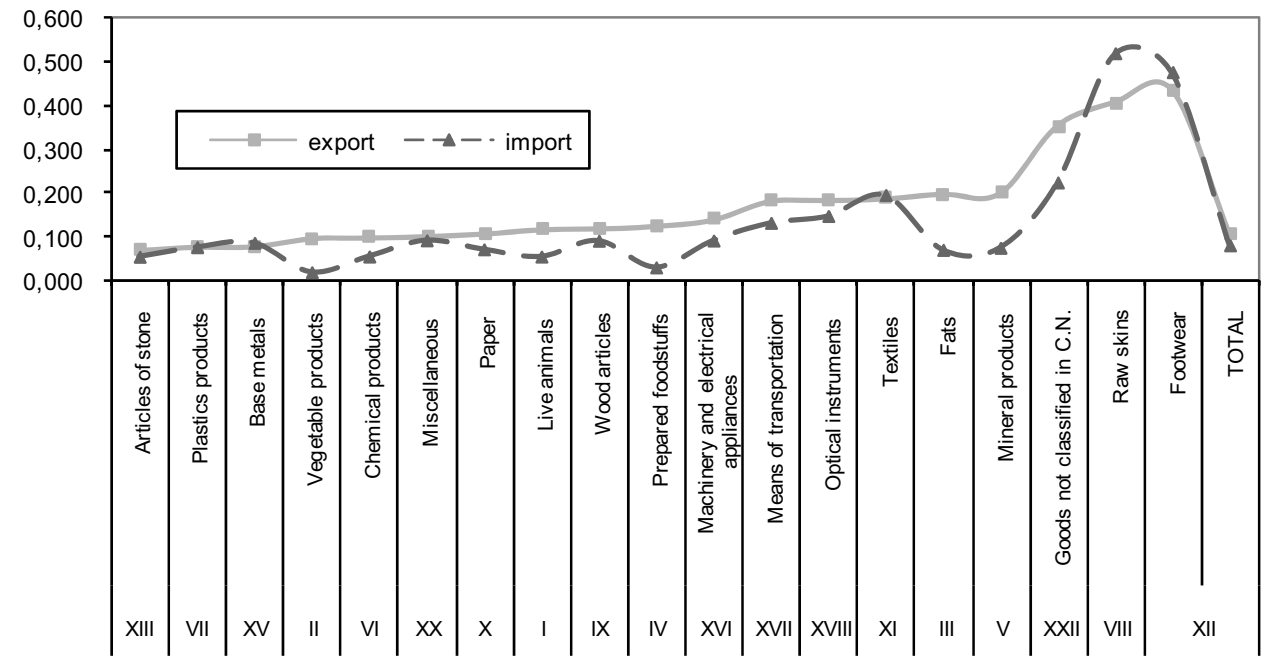

Figure 5. Concentration of the foreign trade by member states of the EU and by
sections of the Combined Nomenclature in 2008 (the value of the Onicescu
informational energy-the corrected formula)
Source: processing by Romanian foreign trade yearbook, National Institute of Statistics, Bucharest

\section{Conclusion}

In conclusion, even though Romania's trade goods are made with more than 200 different countries, most international trade is focused on several dominant partner countries. Geographical orientation as the main destination of exports, respectively, area of origin of Romanian imports in 2008 were EU Member States and between these major trading partners of Romania were Italy, Germany and France. Trade with these 3 countries are characterized by exchanges of goods that generally cover a wide range of products, but at the same time Romania has trading partners such as Luxembourg and Ireland where exchanges of goods have specialized in certain products.

\section{References}

1. Harja E. (2009), Statistics, Matrix Rom Publishing House, Bucharest

2. Jaba E. (1998), Statistics, Economic Publishing House, Bucharest

3. Voineagu V and collaborators (2001), Economic statistics, Tribune Publishing House, Bucharest

4. Collection of Romanian foreign trade yearbook, National Institute of Statistics, Bucharest

5. Collection Monthly Statistical Bulletin of the counties, National Institute of Statistics, Bucharest

6. Own database of Statistical Direction of Bacau County 